\title{
Crystal structure of 3-methylrhodaninecopper(I) iodide
}

\author{
F. G. Moers, W. P. J. H. Bosman and P. T. Beurskens \\ Crystallography Laboratory, University of Nijmegen, \\ Toernooiveld, Nijmegen, The Netherlands
}

(Received 20 September 1971)

\begin{abstract}
The crystal structure of the copper(I) complex $\mathrm{CuI}\left(\mathrm{CH}_{3}-\mathrm{N}-\mathrm{CO}-\mathrm{CH}_{2}-\mathrm{S}-\mathrm{CS}\right)$ has been determined by a three-dimensional $\mathrm{X}$-ray analysis. The monoclinic unit cell, space group $P 2_{1} / c, a=4 \cdot 195(1), b=15.581(2), c=13.885(2) \AA$ and $\beta=$ $114 \cdot 9(1)^{\circ}$, contains four formula-units. Intensities were collected on an automatic diffractometer. The structural parameters were refined by full-matrix least-squares methods to a conventional $R$ value of 0.07 for 1809 non-zero observed reflexions.

In this complex, the copper atom is in tetrahedral coordination with three iodine atoms and the sulphur atom of the thiocarbonyl group of the ligand. The iodine atom is coordinated with three copper atoms. The $\mathrm{Cu}-\mathrm{I}$ distances are 2.683(2), $2.627(2)$ and $2.665(2) \AA$. The distances between neighbouring copper atoms are 3.008(3) and 2.960(3) $\AA$ and the corresponding $\mathrm{Cu}-\mathrm{I}-\mathrm{Cu}$ angles are 68.44(6) and 68-02(6) ${ }^{\circ}$, suggesting weak copper-copper interactions in this complex.
\end{abstract}

\section{Introduction}

In a previous paper, the preparations and properties of rhodanine and 3-substituted rhodanine complexes of copper(I) were reported (Moers \& Steggerda, 1968). From the properties of the copper complexes we proposed a polymeric structure for these complexes, and infrared spectra and $\mathrm{nmr}$ measurements indicated a coordination with the thiocarbonyl group of the ligand.

Polymeric copper(I) complexes are known in which thiourea and its derivatives act as ligands. The copper : ligand ratios are 1:2 in $\mathrm{Cu}$ (thiourea) ${ }_{2} \mathrm{Cl}$ (Spofford \&

Copyright O 1972 Plenum Publishing Company Limited. No part of this publication may be reproduced, stored in a retrieval system, or transmitted, in any form or by any means, electronic, mechanical, photocopying, microfilming, recording or otherwise, without written permission of Plenum Publishing Company Limited. 
Amma, 1968); $1: 3$ in $\mathrm{Cu}$ (thiourea) ${ }_{3} \mathrm{Cl}$ (Okaya \& Knobler, 1964) and 4:9 in $\mathrm{Cu}_{4}$ (thiourea) $)_{9}\left(\mathrm{ClO}_{4}\right)_{4}$ (Vranka \& Amma, 1966). The present study describes the $\mathrm{X}$-ray analysis of a polymeric copper(I) complex in which copper forms a 1:1 complex with the ligand 3-methylrhodanine:<smiles>CN1C(=O)CSC1=S</smiles>

In addition, this crystal structure determination is the first involving a complex with a rhodanine ligand.

\section{Experimental}

\section{Crystal data}

3-methylrhodaninecopper(I) iodide, $\mathrm{CuI}\left(\mathrm{C}_{4} \mathrm{H}_{5} \mathrm{NOS}_{2}\right), F W=337 \cdot 67$, crystallizes from ethanol with well-formed yellow needles elongated along $a$. Weissenberg photographs showed that the crystals were monoclinic with space group $P 2_{1} / c$ (No. 14). From Pt-calibrated Weissenberg photographs around $a$ and $b$, using Ni-filtered $\mathrm{Cu} K \alpha$ radiation $(\lambda=1.5418 \AA$ ), application of a least-squares procedure yielded the unit cell dimensions $a=4 \cdot 195(1), b=15 \cdot 581(2), c=13 \cdot 885$ (2) $\AA, \beta=114.9(1)^{\circ} ; V_{c}=823 \cdot 1(5) \AA^{3}$. The calculated density is $2.72 \mathrm{~g} \mathrm{~cm}^{-3}$, with $Z=4$. The measured density is $2 \cdot 80 \mathrm{~g} \mathrm{~cm}^{-3}$ (pycknometric method). $F(000)=632$. The linear absorption coefficient for molybdenum $K \alpha$ radiation is $\mu=69.63 \mathrm{~cm}^{-1}$.

\section{Intensity data}

A crystal of approximately $0.06 \times 0.14 \times 0.34 \mathrm{~mm}^{3}$ was mounted with the needle axis as rotation axis. Intensities were collected with an automatic Nonius diffractometer, using Zr-filtered Mo-radiation. The scan speed was $1 \cdot 2 \%$ min. After every 20 reflexions, a reference reflexion was measured to detect and allow corrections to be made for slow fluctuations in the primary beam. Of the 2680 attainable symmetry independent reflexions $h k l$ (up to $\sin \theta / \lambda=0.80 \AA^{-1}$ ), 1625 reflexions have been measured above background. Of the 2274 attainable symmetry related reflexions $h k l$ (up to $\sin \theta / \lambda=0 \cdot 70 \AA^{-1}$ ), 1573 reflexions have been measured above background (a reflexion is considered 'above background' if its peak intensity exceeds an instrumentally fixed value set slightly above the average background). Absorption corrections were calculated according to the Busing \& Levy (1957) procedure, using $8 \times 4 \times 10$ volume components and 6 accurately located boundary planes (the absorption factors were in the range 1.4-1.8).

The two symmetry-related sets of reflexions were brought on the same scale and corrected for $\mathrm{Lp}$ factors. The disagreement factor for reflexions common in both sets is:

$$
R^{\prime}=\Sigma|| F_{h k l}|-| F_{h k l}|| / \frac{1}{2}\left[\left|F_{h k l}\right|+\left|F_{h k l}\right|\right]=0.09 .
$$

After completion of the measurements, it became apparent that many reflexions were measured incorrectly because of malfunctioning of the instrument. At that 
time we were not able to remeasure all reflexions, and we decided to solve the structure with the available data. After refinement of the structure until $R=0 \cdot 10$, it became apparent (from a comparison of each of the two sets of data with the calculated structure factors) that often $\left|F_{\text {obs }}\right|$ of one of two symmetry-related reflexions was in reasonable agreement with $\left|F_{\text {calc }}\right|$, while the second $\left|F_{\text {obs }}\right|$ value was relatively low. We therefore rejected the lowest $\left|F_{\text {obs }}\right|$ value for each pair of symmetry-related reflexions. Of the 1896 symmetry-independent non-zero reflexions, we rejected 87 further reflexions (see structure determination).

\section{Structure determination}

The positions of the copper, iodine and the sulphur atoms were determined from the three-dimensional sharpened Patterson function. The method of difference Fourier synthesis gave the positions of the light atoms of the structure, except the hydrogens. The positional and vibrational parameters and the scale factor were refined by full-matrix least-squares calculations, allowing anisotropic vibration of the copper and iodine atoms. The function minimized was $\Sigma w\left(\left|F_{0}\right|-\left|F_{c}\right|\right)^{2}$. After refinement of the structure until $R=0.09$, we calculated the weight $w$ for each reflexion from $w=1 / \sigma^{2}\left(\left|F_{0}\right|\right)$, with $\sigma\left(\left|F_{0}\right|\right)=2.5+0.03\left|F_{0}\right|+0.0001\left|F_{0}\right|^{2}$. The function $\sigma\left(\left|F_{0}\right|\right)$ was found by plotting the r.m.s. of $\left(\left|F_{0}\right|-\left|F_{c}\right|\right)$ against $\left|F_{0}\right| ; 87$ reflexions with ||$F_{0}|-| F_{c} \mid>2 \cdot 5 \sigma\left(\left|F_{0}\right|\right)$ were assumed* to be measured incorrectly and were assigned $w=0$ (the $\left|F_{0}\right| \mid$ and the $\sigma\left(\left|F_{0}\right|\right)$ values are in the ranges 8-230 and $\mathbf{2} \cdot 7-14 \cdot 7$, respectively).

Structure factors calculation resulted in $R=0.079$, and several more cycles of least-squares refinement reduced the conventional $R$ value to 0.067 for 1809 reflexions (excluding the 87 rejected reflexions). After rejecting the incorrectly measured reflexions, only the $x$ parameter of the $C(2)$ atom shifted more than two deviations and therefore we doubled its esd. A final three-dimensional difference map did not indicate any unusual features (the highest peaks were $1.5 \mathrm{e} / \AA^{3}$, found around the positions of the iodine and sulphur atoms and at the expected positions of hydrogen atoms).

Calculations were performed on an IBM 360/50 computer, using programs written by Busing, et al., (1962), Johnson (1965), Ahmed \& Pippy (1968) and several programs written at this laboratory.

\section{Results and discussion}

The atomic parameters are given in table 1 . The structure is illustrated in figures 1 and 2 , and bond distances and angles are given in tables 2 and 3.

The structure may be described in terms of a chain of copper atoms (figure 2) which are connected by bridging iodine atoms. The $\mathrm{Cu}-\mathrm{I}$ distances are 2.683(2),

* We have remeasured a random sample ( 31 reflexions) of the 87 rejected reflexions; the results show that $\left\|F_{o}|-| F_{c}\right\| \leqslant 2 \cdot 7 \sigma\left(\left|F_{o}\right|\right)$ for all reflexions and that most of the rejected reflexions did have incorrectly measured $\left|F_{\mathrm{o}}\right|$ values. 
26 F. G. MOERS, W. P. J. H. BOSMAN AND P. T. BEURSKENS

Table 1. Atomic parameters for $\mathrm{CuI}\left(\mathrm{C}_{4} \mathrm{H}_{5} \mathrm{NOS}_{2}\right)$ with standard deviations

\begin{tabular}{lllll}
\hline Atom & \multicolumn{1}{c}{$x$} & \multicolumn{1}{c}{$y$} & \multicolumn{1}{c}{$z$} & $B\left(\AA^{2}\right)$ \\
\hline I & $0.4462(2)$ & $0.04362(4)$ & $0.14396(5)$ & \\
Cu & $0.7790(5)$ & $0.06654(10)$ & $0.01789(13)$ & \\
S(1) & $0.9426(9)$ & $0.2643(2)$ & $0.1507(2)$ & $2 \cdot 70(4)$ \\
S(2) & $0.5800(8)$ & $0.1949(2)$ & $-0.0686(2)$ & $2 \cdot 57(4)$ \\
O & $0.357(3)$ & $0.4634(7)$ & $0.0820(9)$ & $4 \cdot 0(2)$ \\
N & $0.451(2)$ & $0.3455(5)$ & $-0.0015(7)$ & $2 \cdot 0(1)$ \\
C(1) & $0.631(3)$ & $0.2715(6)$ & $0.0198(8)$ & $2 \cdot 0(1)$ \\
C(2) & $0.518(7)$ & $0.3981(7)$ & $0.0869(9)$ & $2 \cdot 6(2)$ \\
C(3) & $0.810(3)$ & $0.3666(7)$ & $0.1848(9)$ & $2 \cdot 7(2)$ \\
C(4) & $0 \cdot 165(3)$ & $0.3677(7)$ & $-0.1056(9)$ & $2 \cdot 6(2)$
\end{tabular}

$\mathrm{I}$ and $\mathrm{Cu}$ atoms with anisotropic temperature factors:

\begin{tabular}{lllllll}
\multicolumn{8}{c}{$\exp -\left(\beta_{11} h^{2}+\beta_{22} k^{2}+\beta_{33} l^{2}+2 \beta_{12} h k+2 \beta_{13} h l+2 \beta_{23} k l\right)$} \\
\hline Atom & $10^{4} \beta_{11}$ & $10^{4} \beta_{22}$ & $10^{4} \beta_{33}$ & $10^{4} \beta_{12}$ & $10^{4} \beta_{13}$ & $10^{4} \beta_{23}$ \\
\hline I & $417(5)$ & $25 \cdot 8(3)$ & $31 \cdot 1(4)$ & $-1 \cdot 0(9)$ & $47 \cdot 7(1)$ & $-2 \cdot 8(2)$ \\
$\mathrm{Cu}$ & $576(13)$ & $27 \cdot 3(6)$ & $43 \cdot 4(9)$ & $17(2)$ & $56(3)$ & $-0 \cdot 7(6)$ \\
\hline
\end{tabular}

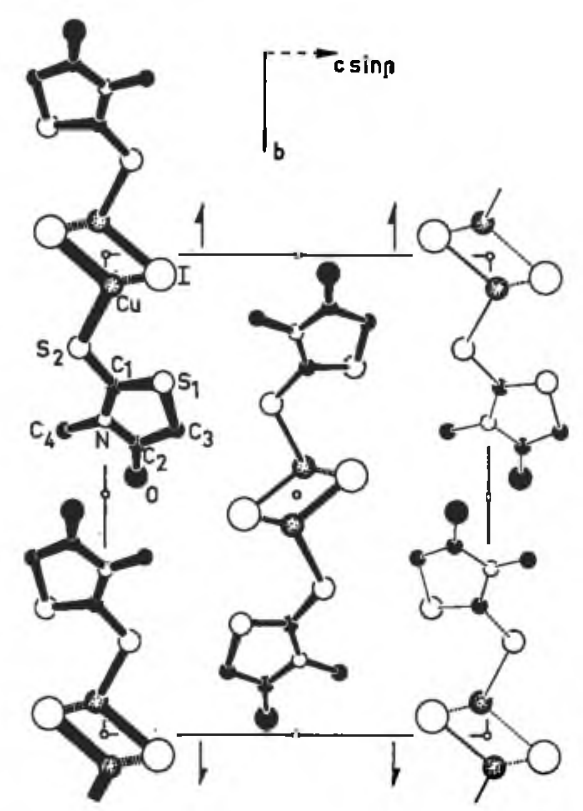

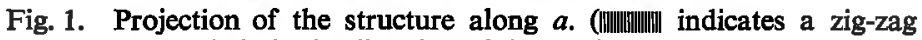
$\mathrm{Cu}-\mathrm{I}$ chain in the direction of the $a$ axis). 


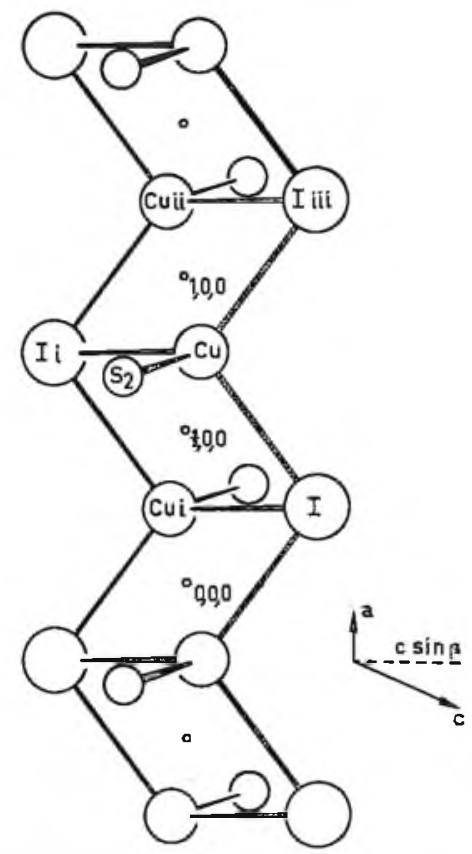

Fig. 2. Projection along $b$ of a copper-coordination chain. For symmetry relations see table 2 .

2.627(2) and 2.665(2) $\AA$. Each copper atom is in tetrahedral coordination with three iodine atoms and one sulphur atom. The $\mathrm{Cu}-\mathrm{S}$ distance is 2.301(3) $\AA$. Within a chain, there are four-membered rings which are of particular interest because of the short $\mathrm{Cu}-\mathrm{Cu}$ distances (2.960(3) and 3.008(3) $\AA$ ) and the sharp

Table 2. Bond distances and angles involving copper

\begin{tabular}{lllr}
\hline & \multicolumn{1}{c}{$\AA$} & & \multicolumn{1}{c}{$\mathrm{deg}}$. \\
\hline $\mathrm{Cu}-\mathrm{I}$ & $2 \cdot 683(2)$ & $\mathrm{I}-\mathrm{Cu}-\mathrm{I}(\mathrm{i})$ & $111 \cdot 6(1)$ \\
$\mathrm{Cu}-\mathrm{I}(\mathrm{i})$ & $2 \cdot 665(2)$ & $\mathrm{I}-\mathrm{Cu}-\mathrm{I}(\mathrm{iii})$ & $104 \cdot 4(1)$ \\
$\mathrm{Cu}-\mathrm{I}(\mathrm{iii})$ & $2 \cdot 627(2)$ & $\mathrm{I}(\mathrm{i})-\mathrm{Cu}-\mathrm{I}(\mathrm{iii})$ & $112 \cdot 0(1)$ \\
$\mathrm{Cu}-\mathrm{S}(2)$ & $2 \cdot 301(3)$ & $\mathrm{I}-\mathrm{Cu}-\mathrm{S}(2)$ & $106 \cdot 4(1)$ \\
$\mathrm{Cu}-\mathrm{Cu}(\mathrm{ii})$ & $2 \cdot 960(3)$ & $\mathrm{I}(\mathrm{i})-\mathrm{Cu}-\mathrm{S}(2)$ & $101 \cdot 4(1)$ \\
$\mathrm{Cu}-\mathrm{Cu}(\mathrm{i})$ & $3 \cdot 008(3)$ & $\mathrm{I}(\mathrm{iii})-\mathrm{Cu}-\mathrm{S}(2)$ & $121 \cdot 1(1)$ \\
& & $\mathrm{Cu}-\mathrm{I}-\mathrm{Cu}(\mathrm{i})$ & $68 \cdot 4(1)$ \\
& & $\mathrm{Cu}-\mathrm{I}(\mathrm{i})-\mathrm{Cu}(\mathrm{ii})$ & $68 \cdot 0(1)$ \\
& & $\mathrm{Cu}-\mathrm{S}(2)-\mathrm{C}(1)$ & $109 \cdot 5(4)$ \\
\hline
\end{tabular}

Symmetry relations: (i) $=1-x, \hat{y}, \bar{z}$; (ii) $=2-x, \hat{y}, \bar{z}$;

(iii) $=1+x, y, z$. 
$\mathrm{Cu}-\mathrm{I}-\mathrm{Cu}$ angles $\left(68.02(6)\right.$ and $\left.68.44(6)^{\circ}\right)$. The bond distances and angles in these rings are given in table 2 . The dihedral angle between neighbouring fourmembered rings is $63 \cdot 4^{\circ}$. The short $\mathrm{Cu}-\mathrm{Cu}$ distances are correlated with small, but significant distortions from tetrahedral coordination of the copper atom $\left(\mathrm{I}-\mathrm{Cu}-\mathrm{I}(\mathrm{i})=111 \cdot 56(7)\right.$ and $\mathrm{I}(\mathrm{i})-\mathrm{Cu}-\mathrm{I}(\mathrm{iii})=111 \cdot 98(7)^{\circ}$, while $\mathrm{I}-\mathrm{Cu}-\mathrm{I}(\mathrm{iii})=$ $\left.104 \cdot 38(7)^{\circ}\right)$. The results suggest weak copper-copper interactions, and these short $\mathrm{Cu}-\mathrm{Cu}$ distances and their accompanying sharp bridge angles are similar to the bridge in dimeric trimethylaluminium, in which the bonding is described with $\mathrm{Al}-\mathrm{C}$ and Al-Al interactions (Lewis \& Rundle, 1953; Vranka \& Amma, 1967). In the thiourea complexes, $\mathrm{Cu}$ (thiourea) ${ }_{2} \mathrm{Cl}$ and $\mathrm{Cu}_{4}$ (thiourea) ${ }_{9}\left(\mathrm{ClO}_{4}\right)_{4}$ (loc. cit.), the bonding is suggested to be analogous to the bonding in dimeric trimethyl-

Table 3. Bond angles and distances within the 3-methylrhodanine ligand. The last column gives the comparable distances in the rhodanine molecule (van der Helm, Lessor \& Merritt, 1962)

\begin{tabular}{|c|c|c|c|c|}
\hline \multicolumn{2}{|c|}{ Bond angles } & \multicolumn{2}{|c|}{ Bond distances } & $\begin{array}{c}\text { Bond distances } \\
\text { in rhodanine } \\
\AA\end{array}$ \\
\hline$S(2)-C(1)-N$ & $125(1)$ & $C(1)-S(2)$ & $1.659(10)$ & $1 \cdot 64$ \\
\hline$C(1)-N-C(4)$ & $125(1)$ & $\mathrm{C}(1)-\mathrm{N}$ & $1 \cdot 342(14)$ & $1 \cdot 37$ \\
\hline $\mathrm{C}(1)-\mathrm{N}-\mathrm{C}(2)$ & $115(1)$ & $\mathrm{N}-\mathrm{C}(4)$ & $1.479(15)$ & \\
\hline $\mathrm{C}(4)-\mathrm{N}-\mathrm{C}(2)$ & $120(1)$ & $\mathrm{N}-\mathrm{C}(2)$ & $1 \cdot 403(20)$ & $1 \cdot 38$ \\
\hline $\mathbf{N}-\mathbf{C}(2)-\mathbf{O}$ & 123(1) & $C(2)-0$ & $1 \cdot 206(22)$ & $1 \cdot 23$ \\
\hline $\mathrm{N}-\mathrm{C}(2)-\mathrm{C}(3)$ & $113(1)$ & $C(2)-C(3)$ & $1.479(22)$ & $1 \cdot 51$ \\
\hline $\mathrm{O}-\mathrm{C}(2)-\mathrm{C}(3)$ & $124(1)$ & $C(3)-S(1)$ & $1 \cdot 815(13)$ & $1 \cdot 82$ \\
\hline$C(2)-C(3)-S(1)$ & $106(1)$ & $S(1)-C(1)$ & $1 \cdot 738(11)$ & $1 \cdot 74$ \\
\hline$C(3)-S(1)-C(1)$ & 92(1) & & & \\
\hline$S(1)-C(1)-S(2)$ & $122(1)$ & & & \\
\hline
\end{tabular}

aluminium, but involving sulphur instead of carbon as bridging atom. In fact, we believe the bonding in the rhodanine complex to be very similar to that in these complexes.

The geometry of the 3-methylrhodanine ligand agrees within one or two standard deviations with the geometry of rhodanine (van der Helm et al., 1962), see table 3. A shortening of the $\mathrm{C}(1)-\mathrm{N}, \mathrm{C}(2)-\mathrm{O}$, and $\mathrm{C}(2)-\mathrm{C}(3)$ distances (about $0.03 \AA$, which is not significant) may be caused by complexing, substitution of $\mathrm{N}-\mathrm{H}$ by $\mathrm{N}-\mathrm{CH}_{3}$, and the absence of hydrogen bonds in 3-methylrhodanine. The C(1)-S(2) distance is only slightly greater than in rhodanine itself, indicating that coordination with the 3-methylrhodanine ligand does not require a lengthening of the $\mathbf{C}(1)-\mathbf{S}(2)$ distance, as was observed also in the thiourea compounds (loc. cit.).

The five-membered ring $S(1), C(1), N, C(2), C(3)$ is nearly planar; the deviations from the least-squares plane through these atoms are 0.00(0) $\AA$ for $S(1),-0 \cdot 03(1)$ 
for $C(1), 0-03(1)$ for $N,-0.05(2)$ for $C(2), 0-00(1)$ for $C(3),-0-07(0)$ for $S(2)$, -0.02 (1) for $C(4)$ and $-0.11(1)$ for $O$. The mean planes through a group of atoms are given by their normal equations referred to an orthogonal set of axes $X, Y$, and $Z$, with $X$ along the $a$ axis, $Y$ in the $(a, b)$ plane and $Z$ along the $c^{*}$ axis. The weights used in the least-squares calculations are based upon the accuracy of the positional parameters. The dihedral angle between the planes through $S(1), C(1), N, S(2)$ and $\mathrm{N}, \mathrm{C}(2), \mathrm{C}(3), \mathrm{O}$ is $5 \cdot 7^{\circ}$.

Non-bonding distances are all in the expected range; the shortest van der Waals contacts are $\mathrm{O} \cdots \mathrm{O}=3 \cdot 12(2)$ and $\mathrm{N} \cdots \mathrm{O}=3 \cdot 42(2) \AA$.

\section{Acknowledgements}

The authors are grateful to Professor Dr Ir J. J. Steggerda for his continuous interest and to Mr J. M. M. Smits for valuable assistance.

\section{References}

Ahmed, F. R. \& Pippy, M. E. (1968) Crystallographic computer programmes (NRC$3,8,12,22)$. World list of Crystallographic Computer Programs 2nd ed. Appendix, p. 52. Busing, W. R. \& Levy, H. A. (1957) Acta Crystallogr. 10, 180.

Busing, W. R., Martin, K. O. \& Levy, H. A. (1962) Fortran least-squares program (ORFLS). Oak Ridge National Laboratory Report 305.

van der Helm, D., Lessor, A. E. \& Merritt, L. (1962) Acta Crystallogr. 15, 1227.

Johnson, C. K. (1965) Fortran thermal-ellipsoid plot program (ORTEP). Oak Ridge National Laboratory Report 3794.

Lewis, P. H. \& Rundle, R. E. (1953) J. Chem. Phys. 21, 986.

Moers, F. G. \& Steggerda, J. J. (1968) J. Inorg. Nucl. Chem. 30, 3217.

Okaya, Y. \& Knobler, C. B. (1964) Acta Crystallogr. 17, 928.

Spofford, W. A. \& Amma, E. L. (1968) Chem. Comm. 405.

Vranka, R. G. \& Amma, E. L. (1966) J. Amer. Chem. Soc. 88, 4270.

Vranka, R. G. \& Amma, E. L. (1967) J. Amer. Chem. Soc. 89, 3121.

National Lending Library Supplementary Publication No. 60039 contains 20 pages of structure factor tables on 1 microfiche. 
